\title{
Automatic Ship Berthing Based on Fuzzy Logic
}

\author{
Van-Suong Nguyen ${ }^{1}$ and Nam-Kyun Im $^{2}$ \\ ${ }^{1}$ Faculty of Navigation, Vietnam Maritime University, 484 Lach Tray Str., Haiphong City, Vietnam \\ ${ }^{2}$ Department of Navigation Science, Mokpo National Maritime University, Mokpo, Korea
}

\section{]jfis}

\begin{abstract}
Because the maneuverability of ship at low speed is reduced significantly, ship berthing is one of most difficult duties that ship master usually has to face as arriving at the port. In order to make sure the safe accomplishment of ship berthing, all steps need to be performed properly. In fact of maritime safety, the tugboats and thrusters are commonly utilized to support crabbing motion of ship in final stage of berthing process before mooring. In addition, because of the nonlinear of ship dynamic on berthing, theories of artificial intelligence are suitable to mimic the actions of ship master in controlling ship berthing automatically. In this article, a support system is proposed to bring ship into berth automatically after using the maneuvering control system. Three fuzzy controllers are established for different tasks of the berthing algorithm. The first controller is designed to control the movement of ship in longitudinal direction toward to the normal of wharf with the ship's propeller, while the task of second controller is to stabilize the relative bearing error with tugboat. The final controller is responsible for bring the ship into wharf according to crabbing motion with bow thruster and tugboat simultaneously. Finally, numerical simulations are carried out to validate the performance of the proposed system. The results show that the berthing support system has good performance for ship.
\end{abstract}

Keywords: Support system for automatic ship berthing, Fuzzy controllers, Tugboat, Bow thruster, Relative bearing

\section{Introduction}

Because of some complicated features in ship motion as moving in low speed, ship berthing is seen as one of most difficult tasks which the ship captain have to face before loading or unloading cargoes. With the hope to invent the real system for automatic ship berthing, modern control and automation theories have been investigated deeply and widely to ship berthing. In order to bring the ship into berth safely and automatically, excellent controllers need to be demanded to regulate the rudder and the propeller properly. Until now, the artificial neural network (ANN) model has been seen as most effective approach to automatic ship berthing. An ANN model for ship berthing was proposed first time by Yamato [1], but his studies were changed to different approach by using expert system. Later on, Im and Hasegawa [2] suggested two parallel neural networks for main controller to obtain excellent results. As continuously developed, some controllers for different zones in a port were considered in [3]. In [4], the authors introduced a virtual window to obtain consistent data for training neural 
network. This controller can be applied for different initial states of ship heading and ship coordinate. In the situation of significant disturbance due to strong wind, a PD based controller was added to keep ship in imaginary line instead of ANN model. Recently, the authors [5] proposed an ANN controller based on head-up coordinate system, this controller is trained by teaching data in an original port and then the ship is controlled automatically into the berth in different ports without retraining the ANN structure. This controller has the advantage of being time-saving, cost-saving and simple structure. However, the use of inputs in head-up coordinate system commonly contains the errors by radar onboard the ship. To overcome the limitations of head-up coordinate system, Nguyen et al. [6] suggested a neural controller with new inputs which are determined by distance measurement system. In comparison with the head-up coordinate system based controller, the proposed controller in this research is more confident and it can be applied for unmanned ship in future. Although, the above mentioned researches [1-6] contributed the significant results to ship berthing, they only focused on how to maneuver automatically the ship from fair-way area to wharf area but not wharf position.

In fact of maritime safety, the berthing process of ship is considered as completion after the ship is pushed into wharf position under desired velocities to hold the mooring lines on land. For that purpose, Im [7] described a neural controller to control bow thruster and the tugboat of ship. In this research, the proposed controller has four outputs which are ruder angle, propeller, the bow thruster and the tugboat. The highlight of this controller is to push the ship to final wharf with assistant of bow thruster and tugboat. In [8], an adaptive controller is developed for crabbing motion of ship berthing under wind. However, this back-stepping technique based controller only can be employed in crabbing motion where the surge speed of ship is zero. Although, these studies suggested the controllers to control the tugboats and bow thruster of ship, the limitations of the above researches are still found and need to be resolved to obtain the perfect system for automatic ship berthing in future.

In this study, a ship berthing support system is proposed to bring ship into berth automatically before mooring by using fuzzy logic. The structure of this system includes three fuzzy logic controllers as follows: first controller is to control the movement of ship in longitudinal direction toward to the normal of wharf; second controller is to stabilize the relative bearing error with tugboat; the final controller is responsible for bring the ship into wharf according to crabbing motion with bow thruster and tugboat simultaneously. These controllers are designed to obtain the actions as human in bring the ship into wharf. The new contributions of this study in comparison with previous researches are represented as follows.

Firstly, in [7], because of using the coordinate and course of ship as inputs in teaching data, the neural controller was trained by teaching data in an original port and could be only utilized to this port. As arriving to a new port, this controller did not have ability to control ship into wharf successfully. Therefore, the controller needs to be retrained by new teaching data. This causes time-consuming and expensive cost. With this research, because the inputs for controllers are distances from the ship to wharf, the fuzzy controllers can apply to different wharfs. It means that this system overcomes the disadvantage of the controller in [7].

Secondly, in [8], the adaptive back-stepping controller was proposed to control the azimuth propellers of cruise ship for crabbing motion, but, not every ship is equipped the modern devices as the azimuth propellers. Additionally, the simultaneous use of tugboat and bow thruster commonly is done for ship berthing process, thus, the back-stepping controller has no ability to apply to this case. Moreover, in process of the design of this controller, the surge speed is assumed as zero during control process. However, in fact, the surge speed is always different with zero. The system proposed by our research does not require any constrain on ship velocities and initial conditions of ship.

Finally, because the dynamic model of berthing system is complex, the approach using fuzzy logic theory by this research to control the stages in berthing process is appropriate and the actions of the proposed system is similar to the inference of ship master in performing the stages of ship berthing.

To validate the effectiveness of the proposed system, numerical simulations are carried out. The results show that the berthing support system has good performance for ship.

This paper is included as follows: mathematical model of ship motion is shown in Section 2. The concept of ship berthing support system is introduced in Section 3. In Section 4, the detail of new system is proposed. Simulation results of the proposed system are presented in Section 5. The conclusion is summarized in Section 6.

\section{Mathematical Model of Ship Motion}

To solve the problems of ship maneuvering or ship control system, the mathematical model of ship needs to be described firstly. This model has to represent exactly the characteristic of 


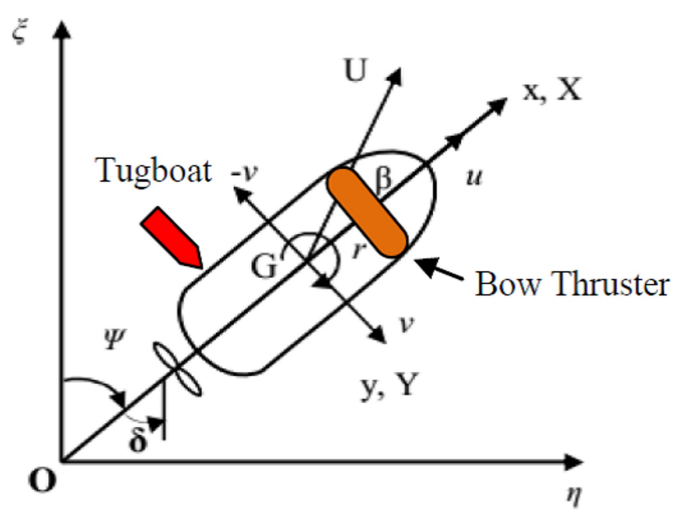

Figure 1. Ship dynamic in Cartesian coordinate system with assistance of bow thruster and tugboat.

ship as real world. In problems of surface ship, the ship motion on directions, such as the surge, sway and yaw is enough to express the dynamic characteristic of the ship on the Cartesian coordinate system (Figure 1).

Among the different kinds of mathematical model of ship, the Maneuvering Modeling Group (MMG) model is employed in this research to show the ship motion during the berthing process, in which the hydrodynamic components such as forces and moments acting on the ship were divided into the separate modules such as the hull, rudder, propeller, tugboat and thruster. According to MMG model, the maneuvering equation of the ship is shown as follows:

$$
\begin{aligned}
& \left(m+m_{x}\right) \dot{u}-\left(m+m_{y}\right) v r=X_{H}+X_{P}+X_{R}, \\
& \left(m+m_{y}\right) \dot{v}+\left(m+m_{x}\right) u r=Y_{H}+Y_{P}+Y_{R}+Y_{T u g}+Y_{T h r}, \\
& \left(I_{z z}+J_{z z}\right) \dot{r}=N_{H}+N_{R}+N_{T u g}+N_{T h r},
\end{aligned}
$$

where $u, v$, and $r$ are the ship's velocity in surge, sway and yaw direction, respectively; $X_{H}, Y_{H}$, and $N_{H}$ are the hydrodynamic forces and moments acting on the ship hull. They are defined by equations of Kijima et al. [9], the detail equation was expressed as in Eq. (2):

$$
\begin{aligned}
X_{H}= & \frac{\rho}{2} L d U^{2}\left(X_{\beta r}^{\prime} \sin \beta+X_{u u}^{\prime} \cos ^{2} \beta \frac{r L}{U}\right), \\
Y_{H}= & \frac{\rho}{2} L d U^{2}\left(Y_{\beta}^{\prime} \beta+Y_{r}^{\prime} \frac{r L}{U}+Y_{\beta \beta}^{\prime} \beta|\beta|+Y_{r r}^{\prime} \frac{r L}{U}\left|\frac{r L}{U}\right|\right. \\
& \left.+Y_{\beta \beta}^{\prime} \beta^{2} \frac{r L}{U}+Y_{\beta r r}^{\prime} \beta\left(\frac{r L}{U}\right)^{2}\right), \\
N_{H}= & \frac{\rho}{2} L^{2} d U^{2}\left(N_{\beta}^{\prime} \beta+N_{r}^{\prime} \frac{r L}{U}+N_{\beta \beta}^{\prime} \beta|\beta|+N_{r r}^{\prime} \frac{r L}{U}\left|\frac{r L}{U}\right|\right.
\end{aligned}
$$

$$
\left.+N_{\beta \beta}^{\prime} \beta^{2} \frac{r L}{U}+N_{\beta r r}^{\prime} \beta\left(\frac{r L}{U}\right)^{2}\right)
$$

where $X_{\beta r}^{\prime}, X_{u u}^{\prime}, \ldots, N_{\beta \beta r}^{\prime}$, and $N_{\beta r r}$ are hydrodynamic coefficients which are estimated as the method described by Kijima et al. [9].

The longitudinal force of the propeller is determined as follows:

$$
\begin{aligned}
& X_{P}=\left(1-t_{P}\right) T, \\
& T=\rho D_{p}^{4} n^{2} K_{T}(J) .
\end{aligned}
$$

The hydrodynamic forces and moment by the rudder are expressed as the following equations:

$$
\begin{aligned}
& X_{R}=-\left(1-t_{R}\right) F_{N} \sin \delta, \\
& Y_{R}=-\left(1+a_{H}\right) F_{N} \cos \delta, \\
& N_{R}=-\left(x_{R}+a_{H} x_{H}\right) F_{N} \cos \delta,
\end{aligned}
$$

where

$$
F_{N}=\frac{\rho}{2} f_{\alpha}(\Lambda) A_{R} U_{R}^{2} \sin \alpha_{R}
$$

Considering the dynamic model of bow thruster for ship maneuvering, method of Hawkins et al. [10] was adopted. The expression is shown as follows:

$$
T=512 .\left(\frac{w_{o}^{2} \cdot L^{3} \cdot H}{M_{o}^{2}}\right),
$$

where $T$ is total lateral thrust of impeller and surfaces forces; $w_{o}$ and $L$ are rate of turning and length on load water line; $H$ is ship's draft; $M_{o}$ is rotation rate constant.

Let $T_{f}$ and $T_{S}$ are the outputs from bow and stern thruster respectively, then the forces in the $y$-axis and moments in the $z$-axis yielded by side thrusters are expressed by the following equations:

$$
\left\{\begin{array}{l}
Y_{T h r}=T_{f}+T_{S}, \\
N_{T h r}=T_{f} x_{b}+T_{S} x_{s} .
\end{array}\right.
$$

Similarly, the force and moment acting on the ship given by tugboat are shown as follows:

$$
\left\{\begin{array}{l}
Y_{T u g}=T u g_{b}+T u g_{S}, \\
N_{T} u g=T u g_{b} m_{b}+T u g_{S} m_{S},
\end{array}\right.
$$

In this research, the thruster is only used in bow position 
Table 1. Principle particular of the ship

\begin{tabular}{lc}
\hline \multicolumn{1}{c}{ Type } & Training ship \\
\hline Length overall & $103 \mathrm{~m}$ \\
Length between perpendicular & $94 \mathrm{~m}$ \\
Breadth & $15.6 \mathrm{~m}$ \\
Draft & $5.4 \mathrm{~m}$ \\
Thruster (Bow) & $49000 \mathrm{~N}$ \\
Transverse projected area & $183.3 \mathrm{~m}^{2}$ \\
Lateral projected area & $1053.7 \mathrm{~m}^{2}$ \\
\hline
\end{tabular}

and tugboat is also in stern area. Thus, the components $T_{S}$ and $\mathrm{Tug}_{S}$ become zero in Eq. (7) and Eq. (8), respectively.

In this study, in order to predict the hydrodynamic coefficients, a training ship named SAENURI of Mokpo National Maritime University was employed as the model ship. The particular of this ship is represented as Table 1.

\section{The Concept of Automatic Berthing Support System for Ship}

In this part, the stages of ship berthing are introduced to show the necessary of the automatic berthing support system for ship. Moreover, the concept of proposed system is also presented.

In fact of maritime operation, the ship is maneuvered into wharf by experienced ship master or pilot. The process is divided into two stages (Figure 2) as follows: first stage, the ship's heading and speed is controlled by changing the rudder and propeller to bring the ship toward near wharf; second one, the ship's thrusters and tugboats are usually employed to push the ship in wharf for mooring. To automatize the ship berthing process in future, many studies have been performed to develop this system.

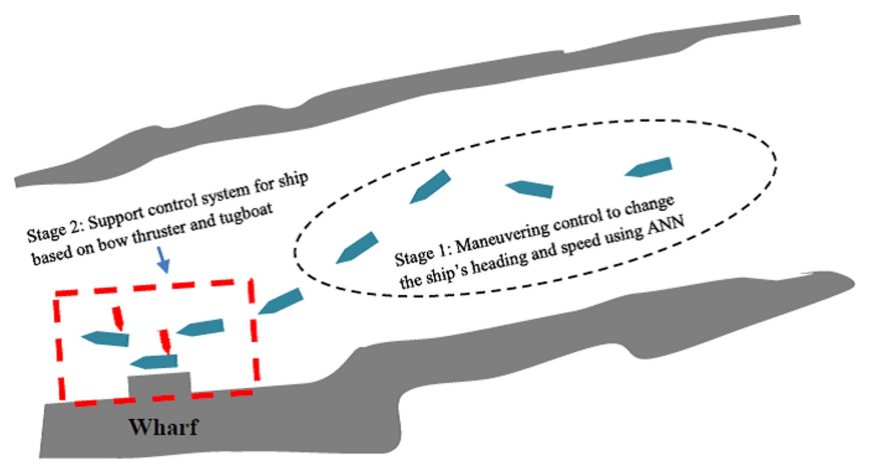

Figure 2. Stages in berthing problem of ship.

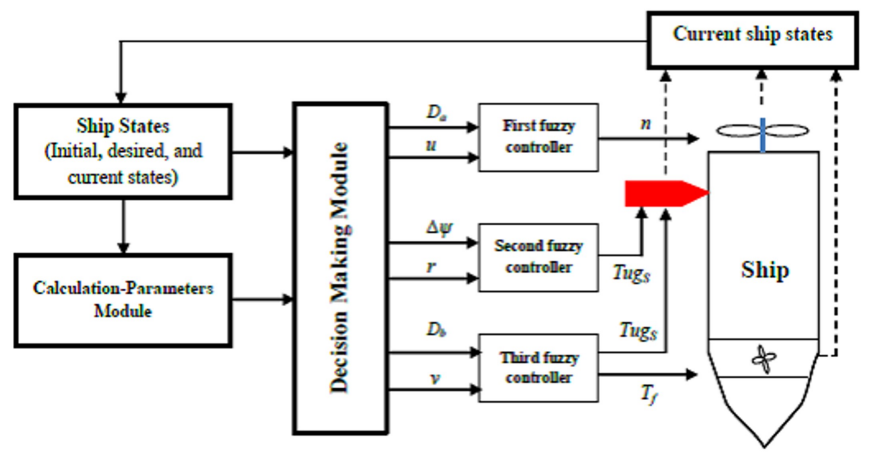

Figure 3. Block diagram of automatic ship berthing support system.

In researches of [1, 3, 5, 7, 9], neural network controllers were proposed to automatically maneuver the ship by changing the ship's rudder and propeller. The principle of those controllers is to mimic actions which are trained by teaching data in advance. The ship's rudder is first altered to bring the ship heading into an appropriate approach direction, the main engine is then stopped in certain time to ensure the ship near wharf. Because the ship cannot be controlled by rudder after stopping engine, those controllers only can be used to control the ship automatically in Stage 1 (Figure 2).

In principle, the ship berthing is considered as accomplishment as the ship is parallel to wharf and distance to wharf is suitable for mooring lines. To do so, some researches were also suggested by using auxiliary devices such as tugboat, thruster and azimuth propeller in Stage 2 (Figure 2) as studies in [7, 8]. But, as mentioned in above, the drawbacks have been still found out in these researches. In this research, to overcome those problems, a fuzzy logic based automatic support system is proposed for ship berthing using the ship's propeller, the bow thruster and tugboat.

\section{The Proposed Support System for Automatic Ship Berthing Using Fuzzy Logic}

\subsection{The Structure of Proposed System}

As shown in Figure 3, the proposed system in this research includes the following modules:

Ship States module: Initial and desired states of ship is created in this block. The state consists of ship position, ship course, relative bearing to wharf, and ship's velocities.

Calculation-Parameter module: Distance to the normal of wharf $\left(D_{a}\right)$, distance from ship to wharf $\left(D_{b}\right)$, and relative bearing from ship to wharf $(\psi R)$ are determined in this module. 


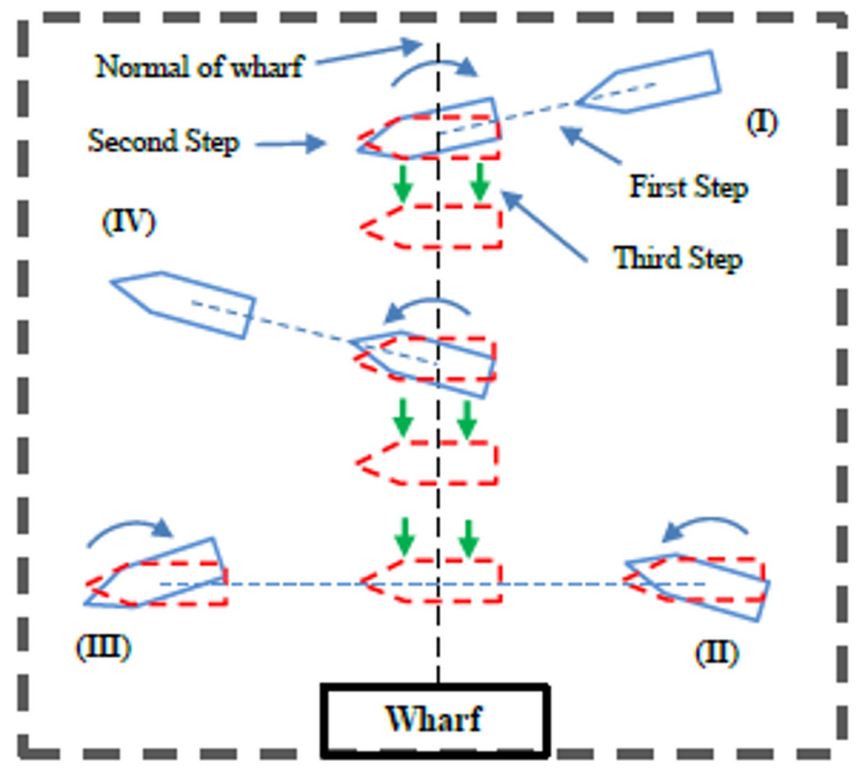

Figure 4. The principle of automatic support system for ship berthing.

Decision Making module: The task of this module is to compare the current states with the desired states of ship and to make decision of selecting the suitable controller for steps.

Fuzzy controllers: The control signals are obtained from the controllers to regulate the main propeller, bow thruster, and tugboat.

\subsection{The Control Algorithm of Proposed System}

After completing the maneuver process by neural network controllers, this system as Figure 4 is switched on. The main task of this system is to control automatically the ship by regulating the main propeller, the bow thruster and tugboat. According to the initial states of ship, the order of controllers is chosen by decision-making module so that the total distance of ship from the initial position to wharf $\left(D_{a}+D_{b}\right)$ is min, as shown in Figure 5.

In cases (I, IV): The working process of this system is explained as following steps:

First step: At the initial state of ship, the first fuzzy controller is used to bring the ship according to longitudinal direction into anywhere on the normal of wharf.

Second step: The second fuzzy controller is employed to regulate the ship's rotation so that the ship's heading is parallel to wharf direction.

Final step: To push the ship into wharf as crabbing motion, the third fuzzy controller is applied.

Conversely, in cases (II, III): The second fuzzy controller

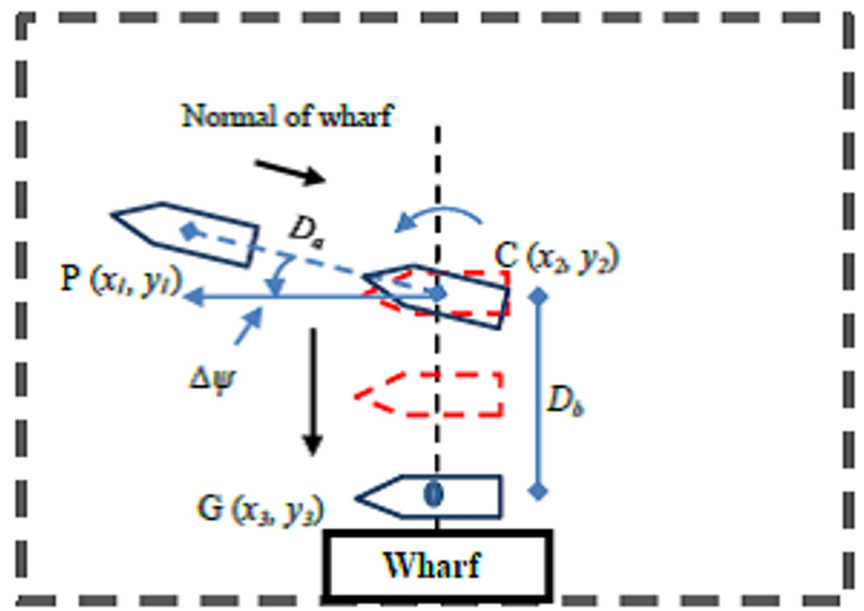

Figure 5. The parameters used in this system.

is first used to turn the ship to be parallel to wharf direction. The first fuzzy controller is then activated to control ship in longitudinal direction by the main propeller.

On the final step to push the ship in wharf as crabbing motion, if the distance from ship to normal of wharf and error of relative bearing exist, then the first and second steps are activated again to ensure the safety for ship.

\subsection{Calculation Parameters Module}

Calculation-Parameter module is used to calculate the inputs for the controllers. As presented in Figure 5, these parameters are found out by following formulas:

$\left\{\begin{array}{l}\text { Relative beariing error: } \Delta \psi=\psi-\psi_{\mathrm{d}}\left(\psi_{\mathrm{d}}=90^{\circ}\right), \\ \text { Distance to normal of wharf: } \\ \qquad D_{a}=\sqrt{\left(x_{1}-x_{2}\right)^{2}+\left(y_{1}-y_{2}\right)^{2}}, \\ \text { Distance to wharf: } D_{b}=\sqrt{\left(x_{3}-x_{2}\right)^{2}+\left(y_{3}-y_{2}\right)^{2}} .\end{array}\right.$

The parameters, such as $u$ surge velocity, $v$ sway velocity, and $r$ yaw rate, are determined by Eq. (1). In fact of maritime, these parameters are calculated on board by log speed and inertial measurement unit. Anymore, the value $\psi$ and distances $\left(D_{a}, D_{b}\right)$ are determined by gyro compass and global positioning system.

\subsection{Fuzzy Logic Controllers}

This proposed system includes three fuzzy controllers to bring the ship into the wharf. The reason to choose fuzzy logic for regulating the ship berthing system is the inference ability of this tool, which has ability to perform the stages of berthing 
Table 2. The particular of fuzzy controllers

\begin{tabular}{lc}
\hline \multicolumn{1}{c}{ Fuzzy inference system type } & Mamdani \\
\hline Input number & 2 \\
Output number & 1 \\
AND method & MIN \\
OR method & MAX \\
Defuzzification & Bisector \\
Implication & MIN \\
Aggregation & MAX \\
\hline
\end{tabular}

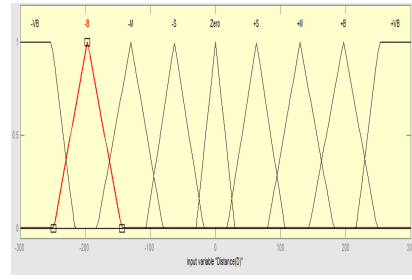

(a)

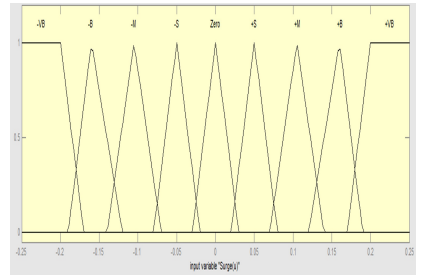

(b)
Figure 6. The membership functions of inputs of first fuzzy controller: (a) distant to normal of wharf and (b) surge velocity.

process as human. Three fuzzy controllers in this research are programmed by fuzzy tool in MATLAB 2014. The fuzzy controllers are designed in same way, hence, their particular are same and shown as in Table. 2. The first controller is to control ship with the ship's propeller. The second one has a duty to rotate the ship with tugboat. The final one is used to push the ship with bow thruster and tugboat in ship's stern. The detail of them is represented in this part as follows:

First fuzzy controller: This controller is employed to bring the ship according to longitudinal direction into position on the normal of wharf. The ship is controlled to go ahead or astern by changing the direction of propeller's rotation. This controller has two inputs and one output. Their inputs consist of distance to normal of wharf and the ship's surge velocity, the output is the propeller speed. The membership functions of two inputs are presented as Figure 6. There are nine membership functions in inputs and outputs to control the propeller speed of ship, which have linguistics variables such as: $-\mathrm{VB},-\mathrm{B},-\mathrm{M},-\mathrm{S}$, Zero, $+\mathrm{S},+\mathrm{M},+\mathrm{B},+\mathrm{VB}$.

The membership function of output and table of rules are shown as Figure 7.

In this research, the distance to normal of wharf is limited in range (from $-300 \mathrm{~m}$ to $300 \mathrm{~m}$ ). The surge velocity is from $-0.25 \mathrm{~m} / \mathrm{s}$ to $0.25 \mathrm{~m} / \mathrm{s}$, and the output is determined from -1.0

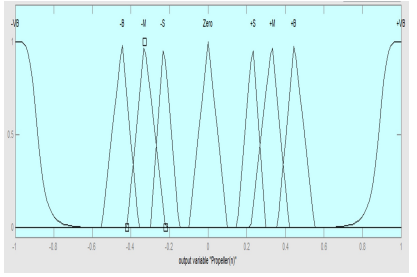

(a)

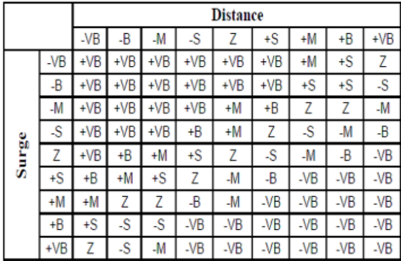

(b)
Figure 7. The membership functions of output and rules for first fuzzy controller: (a) propeller (rps) and (b) rules of first controller.

rps to 1.0 rps.

Second fuzzy controller: The task of this controller is to control tugboat which pushes and pulls the stern of ship for stabilizing the relative bearing to 90 degree. The ship is brought into the heading which is parallel to wharf. Two inputs and one output are also established for this controller. The inputs consist of relative bearing error and yaw rate, the output is the tug force. Seven membership functions in inputs and outputs are built up to control the propeller speed of ship, which have linguistics variables, such as $-\mathrm{B},-\mathrm{M},-\mathrm{S}$, Zero, $+\mathrm{S},+\mathrm{M},+\mathrm{B}$. The membership functions of these parameters are shown as Figures 8 and 9.

Relative bearing error is from -30 degree to 30 degree. The yaw rate is limited from $-1.0 \mathrm{~m} / \mathrm{s}^{2}$ to $1.0 \mathrm{~m} / \mathrm{s}^{2}$, and the output is determined from $-10,000 \mathrm{~N}$ to $10,000 \mathrm{~N}$. In the membership

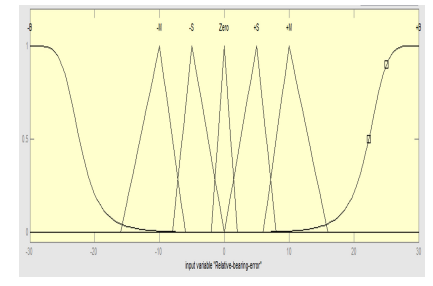

(a)

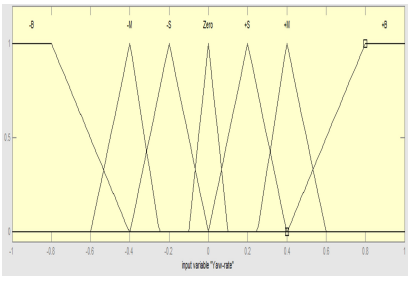

(b)
Figure 8. The membership functions of inputs of second fuzzy controller: (a) relative bearing error and (b) yaw rate.

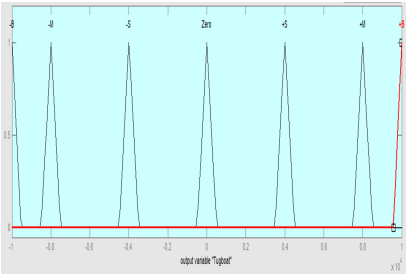

(a)

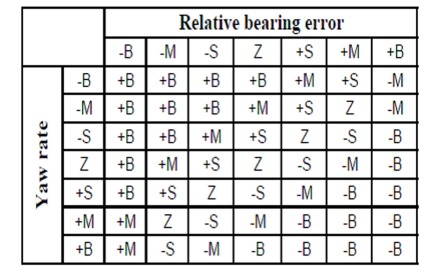

(b)
Figure 9. The membership functions of output and rules for second fuzzy controller: (a) tug force (N) and (b) rules of second controller. 
functions of tugboat force, there are seven triangle zones which are distributed symmetrically by "0" value. Three zones at negative axis are used to push the stern of ship from starboard side to port side. Three zones at opposite axis are applied to pull the stern from portside to starboard side.

Third fuzzy controller: This controller is applied to simultaneously control the forces generated from tugboat and bow thruster for pushing and pulling the ship as crabbing motion to wharf. This controller has also two inputs and one output like two above mentioned controllers. The inputs include distance to wharf and sway velocity of ship, the output is one signal used equally for both tug force and bow thruster. The membership functions of inputs are presented as Figures 10 and 11. Seven membership functions in inputs and outputs are set to control the bow thruster and tugboat at stern of ship, which have linguistics variables, such as $-\mathrm{B},-\mathrm{M},-\mathrm{S}$, Zero, $+\mathrm{S},+\mathrm{M},+\mathrm{B}$.

The distance to wharf is from $-300 \mathrm{~m}$ to $300 \mathrm{~m}$. The sway velocity is from $-1.0 \mathrm{~m} / \mathrm{s}$ to $1.0 \mathrm{~m} / \mathrm{s}$, and the output is determined from $-10,000 \mathrm{~N}$ to $10,000 \mathrm{~N}$. Similarly, the membership functions of tugboat and bow thruster forces contain seven triangle zones. Three zones at negative axis are used to push the stern of ship from starboard side to port side. The other ones at opposite axis are employed to pull the stern from portside to starboard side.

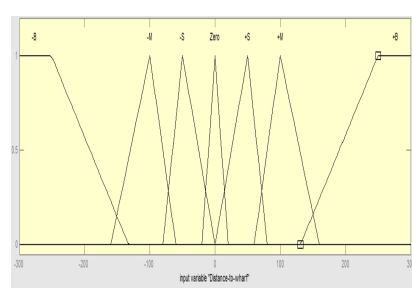

(a)

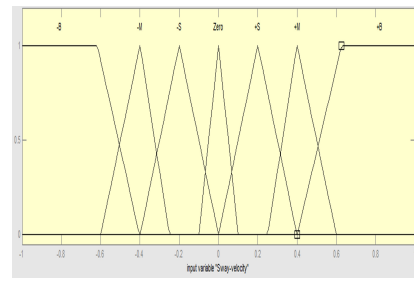

(b)
Figure 10. The membership functions of inputs of third fuzzy controller: (a) distance of wharf and (b) sway velocity.

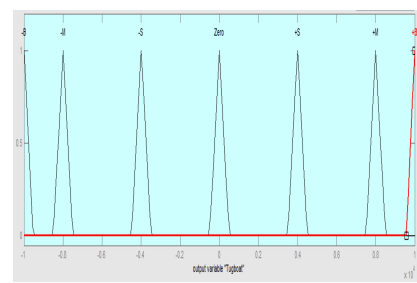

(a)

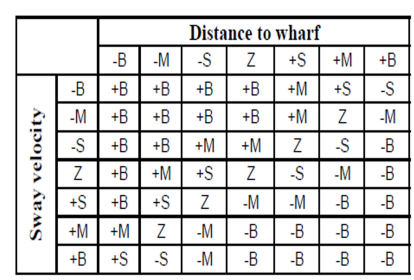

(b)
Figure 11. The membership functions of output and rules for third fuzzy controller: (a) tug and thruster forces and (b) rules of third controller.

\section{Numerical Simulation for Validation}

After completing the maneuvering control process with the ship's rudder, this proposed system is employed to support the final stages before mooring on shore. In this part, numerical simulations are carried out to validate the proposed system for supporting automatic ship berthing control. The ship has initial states as $\left(\nu / L, \xi / L, \psi, u, v, r, r p s, \delta_{\text {ord }}, B o w, T u g\right)$, where $L$ is the perpendicular length of the ship. The control signals from fuzzy controllers are calculated based on inference rules.

In the first case, the ship states respectively are $(1,1,250$, $0.25,0,0,0,0,0,0)$. The ship is at right of the normal of wharf with $0.25 \mathrm{~m} / \mathrm{s}$ in surge velocity and $112 \mathrm{~m}$ in distance, the propeller is operated in ahead and astern to bring the ship in normal of wharf. In the second stage, tugboat is pushed from starboard side $4,000 \mathrm{~N}$ to turn the ship heading to 90 degree in relative bearing. The third step, the tugboat is also used up to $4,000 \mathrm{~N}$, combined with bow thruster to bring the ship into wharf in crabbing direction (Figure 12).

In the second case, the ship states respectively are $(1.5,2$, $280,0.25,0,0,0,0,0,0)$. The ship heading at initial time is 280 degree, the surge velocity of ship is at right of the normal of wharf with $0.25 \mathrm{~m} / \mathrm{s}$ and $164 \mathrm{~m}$ in distance, In the first

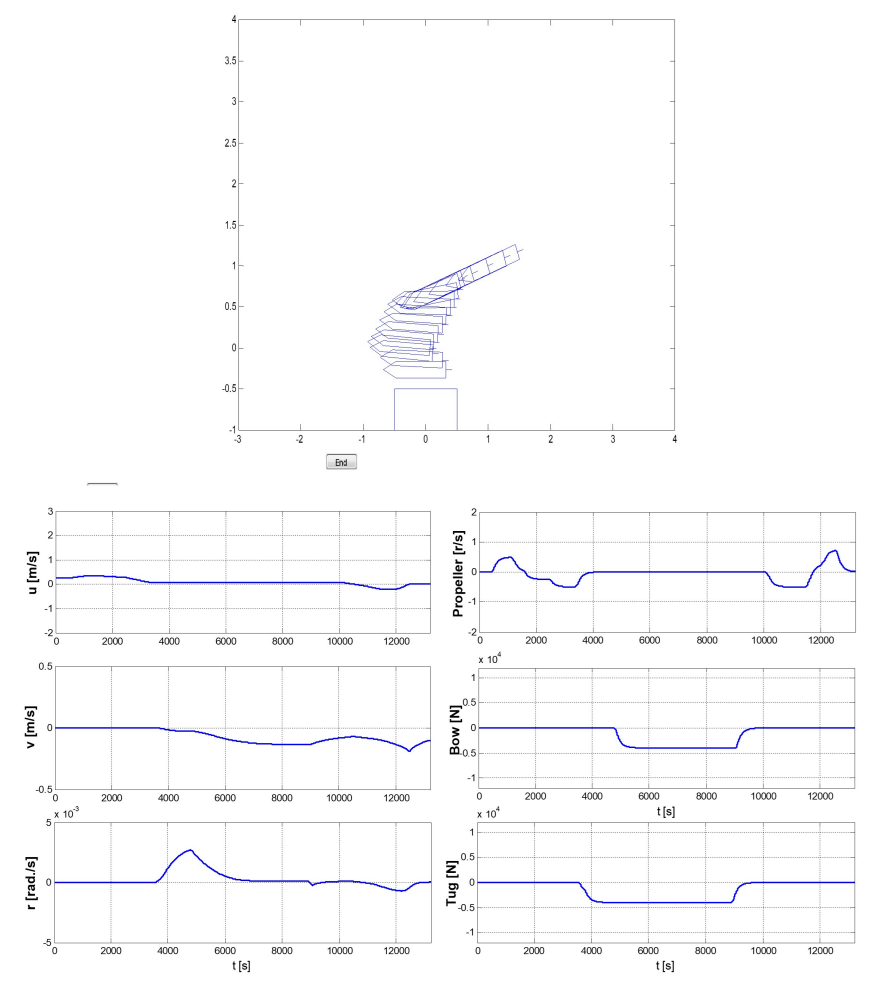

Figure 12. Simulation result for first case. 


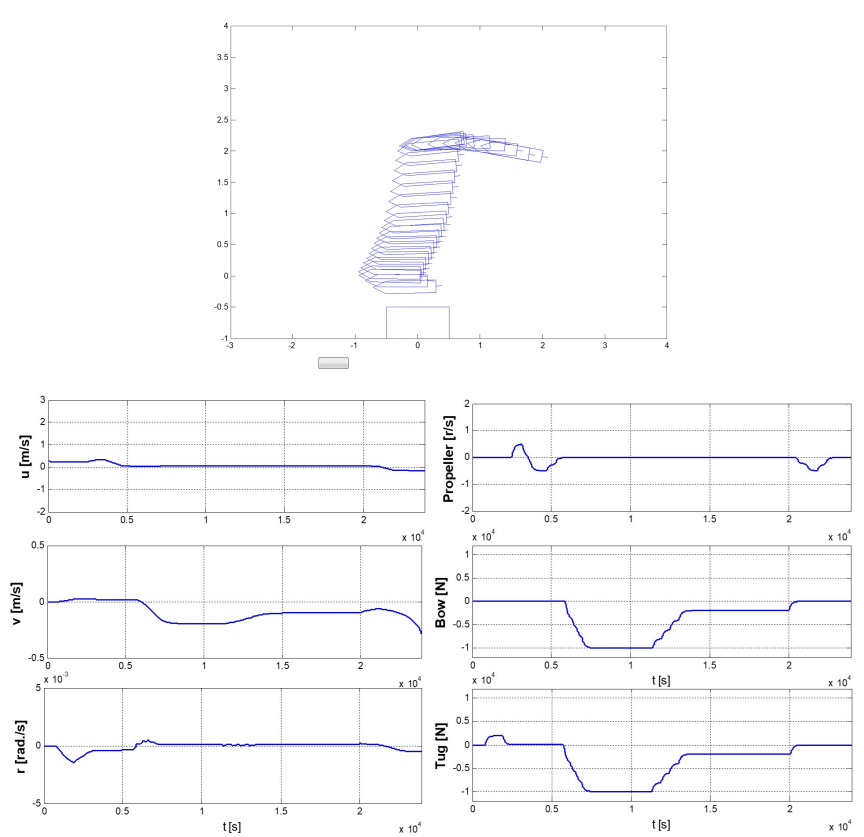

Figure 13. Simulation result for second case.

stage, tugboat is applied to pull the stern of ship from port side to starboard side with $2,000 \mathrm{~N}$ in force for turning the ship heading to 90 degree in relative bearing. The next stage, the propeller is operated to bring the ship toward normal of wharf. In the final step, the tugboat and bow thruster are used up to $10,000 \mathrm{~N}$ and then reduced gradually to push the ship into wharf (Figure 13).

In the third case, the ship states respectively are $(-1.5,1.5$, $280,0.25,0,0,0,0,0,0)$. The surge velocity of ship is at left of the normal of wharf with $0.25 \mathrm{~m} / \mathrm{s}$ and $164 \mathrm{~m}$ in distance. In the first stage, the propeller is rotated backward to make ship's movement to go astern and then the ship is braked up by rotating the propeller forward. This action is done to bring the ship toward normal of wharf. In the second stage, tugboat pulls the stern of ship from port side to starboard side with 2,000 $\mathrm{N}$ in force. The final stage, the ship is brought into wharf by forces from bow thruster and tugboat at stern. Numerical result are shown as Figure 14.

Similarly, the numerical simulations for different cases also are can be performed to validate the effectiveness of proposed system. Results show that this system has performance to support the ship in automatic ship berthing process. After using the neural network controller to manoeuver ship with the ship rudder, this system is useful to bring the ship toward wharf before mooring.

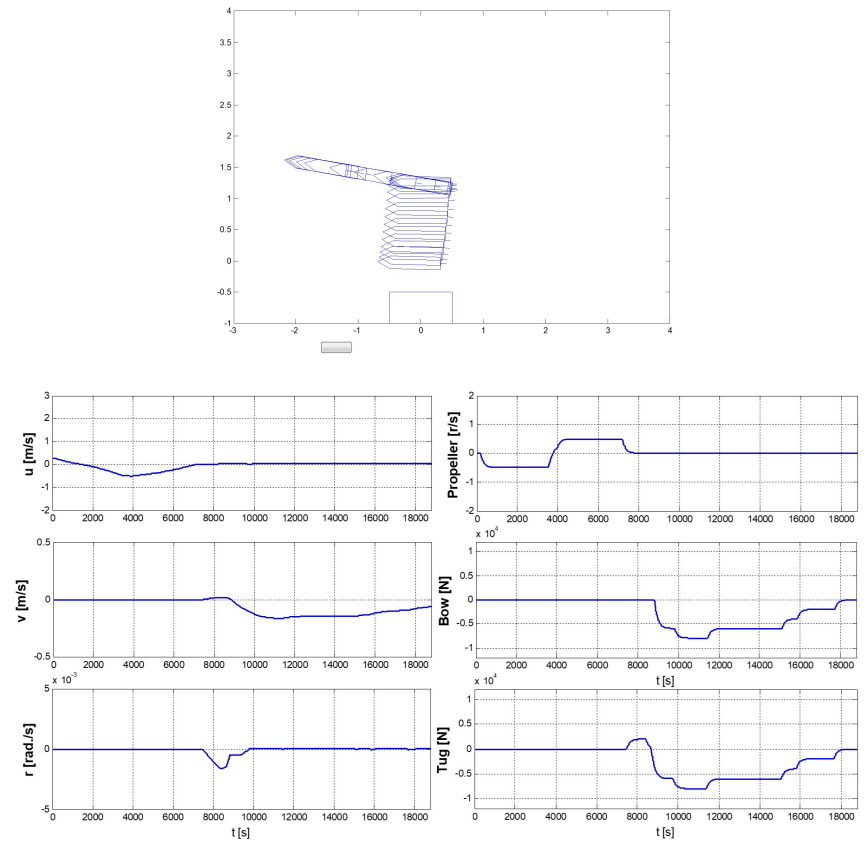

Figure 14. Simulation result for third case.

\section{Conclusions}

In this study, support system for automatic ship berthing is proposed. The conclusion can be summarized as follows:

- The automatic support system for ship berthing was proposed using the main propeller, bow thruster and tugboat. This proposed system is used after the maneuvering control system has finished their task in changing the ship's heading by rudder.

- The fuzzy logic theory was employed in designing three controllers for different tasks in this system. This system is suitable for ship berthing because the fuzzy logic has ability to operate the stages of ship berthing as human.

- Numerical simulations were performed in different cases. The results showed the performances of the proposed system.

\section{References}

[1] H. Yamato, "Automatic berthing by the neural controller," in Proceedings of the 9th Ship Control Systems Symposium, Bethesda, MD, 1990, pp. 3183-3201.

[2] N. Im and K. Hasegawa, "A study on automatic ship berthing using parallel neural controller," Journal of the 
Kansai Society of Naval Architects of Japan, vol. 236, pp. 65-70, 2001. https://doi.org/10.14856/jksna.2001.65

[3] N. Im, S. K. Lee, and D. B. Hyung, "An application of ANN to automatic ship berthing using selective controller,' TransNav: International Journal on Marine Navigation and Safety of Sea Transportation, vol. 1, no. 1, pp. 101$105,2007$.

[4] Y. A. Ahmed and K. Hasegawa, "Automatic ship berthing using artificial neural network trained by consistent teaching data using nonlinear programming method," Engineering Applications of Artificial Intelligence, vol. 26, no. 10, pp. 2287-2304, 2013. https://doi.org/10.1016/j.engappai. 2013.08.009

[5] N. K. Im and V. S. Nguyen, "Artificial neural network controller for automatic ship berthing using head-up coordinate system," International Journal of Naval Architecture and Ocean Engineering, vol. 10, no. 3, pp. 235-249, 2018. https://doi.org/10.1016/j.ijnaoe.2017.08.003

[6] V. S. Nguyen, V. C. Do, and N. K. Im, "Development of automatic ship berthing system using artificial neural network and distance measurement system," International Journal of Fuzzy Logic and Intelligent Systems, vol. 18, no. 1, pp. 41-49, 2018. https://doi.org/10.5391/IJFIS.2018. 18.1 .41

[7] N. Im, "A study on ship automatic berthing with assistance of auxiliary devices," International Journal of Naval Architecture and Ocean Engineering, vol. 4, no. 3, pp. 199 210, 2012. http://doi.org/10.2478/IJNAOE-2013-0090

[8] J. Y. Park and N. Kim, "Design of an adaptive backstepping controller for auto-berthing a cruise ship under wind loads," International Journal of Naval Architecture and Ocean Engineering, vol. 6, no. 2, pp. 347-360, 2014. https://doi.org/10.2478/IJNAOE-2013-0184
[9] K. Kijima, T. Katsuno, Y. Kakiri, and Y. Furukawa, “On the maneuvering performance of a ship with the parameter of loading condition," Journal of the Society of Naval Architects of Japan, vol. 168, pp. 141-148, 1990. https: //doi.org/10.2534/jjasnaoe1968.1990.168_141

[10] S. Hawkins, R. Taggart, and E. D. Hoyt, "The use of maneuvering propulsion devices on merchant ships,'Taggart (Robert) Incorporated, Fairfax, VA, Report No. RT-8518, 1965.

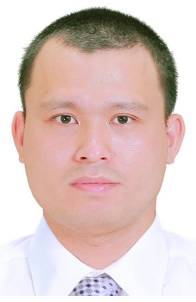

Van-Suong Nguyen received his M.Sc. degree in Navigation Science in 2012 from Vietnam Maritime University and his Ph.D. degree in Maritime Safety System in 2016 from Mokpo National Maritime University, Korea. Since 2010, he has worked as lecturer in Vietnam Maritime University. His research interests include marine navigation, ship control and automation, maritime traffic, and ocean engineering.

E-mail: nguyenvansuong@vimaru.edu.vn

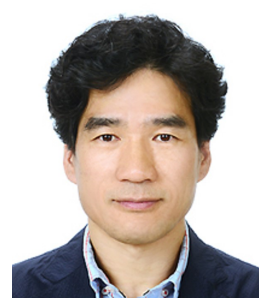

Nam-Kyun Im received his M.Sc. degree in Navigation Science in 1992 from Korea Maritime University and his Ph.D. degree in Naval Architecture and Ocean Engineering in 2002 from Osaka University, Japan. After that, he worked at Ship and Ocean Research Center of Samsung Heavy Industry around 3 years. He is currently professor in Mokpo National Maritime University. His research fields are as follows: ship automatic control study, ship maneuvering simulation and its applications, marine traffic simulation, ship free running model, and marine/ship environmental issues.

E-mail: namkyun.im@mmu.ac.kr 